University of Nebraska - Lincoln

DigitalCommons@University of Nebraska - Lincoln

Faculty Publications from the Harold W. Manter Laboratory of Parasitology

1997

\title{
Paradigm Shifts and Tapeworm Systematics
}

\author{
Eric P. Hoberg \\ United States Department of Agriculture, ehoberg@ggpl.arsusda.gov \\ Scott Lyell Gardner \\ University of Nebraska - Lincoln, slg@unl.edu \\ Ronald A. Campbell \\ University of Massachusetts - Dartmouth
}

Follow this and additional works at: https://digitalcommons.unl.edu/parasitologyfacpubs

Part of the Parasitology Commons

Hoberg, Eric P.; Gardner, Scott Lyell; and Campbell, Ronald A., "Paradigm Shifts and Tapeworm Systematics" (1997). Faculty Publications from the Harold W. Manter Laboratory of Parasitology. 83. https://digitalcommons.unl.edu/parasitologyfacpubs/83

This Article is brought to you for free and open access by the Parasitology, Harold W. Manter Laboratory of at DigitalCommons@University of Nebraska - Lincoln. It has been accepted for inclusion in Faculty Publications from the Harold W. Manter Laboratory of Parasitology by an authorized administrator of DigitalCommons@University of Nebraska - Lincoln. 


\title{
News: Paradigm Shifts and Tapeworm Systematics
}

\author{
E. P. Hoberg, S. L. Gardner and R. A. Campbell
}

\section{Lincoln, Nebraska: October 1996}

The phylogeny of tapeworms provided the focus for the 2nd International Workshop for Tapeworm Systematics, which led to the development of novel hypotheses from the ordinal to the species level for taxa of the Eucestoda. Conceptual roots for this meeting emanated from discussions initiated during the Ist Workshop chaired by Claude Vaucher and Jean Mariaux at the Museum of Natural History, Geneva in 1993 (Ref. 1).

Brooks et al. ${ }^{2}$ were the first to apply cladistic methods to preliminary assessments of the phylogeny of the major lineages and orders of the Eucestoda. In addition, since the late 1970s, there have been phylogenetic studies of selected taxa of tapeworms. ${ }^{3}$ Although the most recent diagnostic keys provided comprehensive coverage to the generic level, there was no general attempt to reflect evolutionary relationships. ${ }^{4}$ However, assessments of phylogenetic diversity become increasingly important with the advent of biodiversity programs, including analyses of hostparasite co-speciation and historical biogeography, ${ }^{5}$ and strategic research involving agriculturally and medically important taxa.

\section{Novel Approaches to Old Questions}

Evolutionary relationships of the eucestodes have received intense but sporadic attention over the past century, but there has never been general agreement among the various hypotheses. ${ }^{2,6}$ Lack of consensus has resulted from conflicts over the adequacy of different classes of characters as indicators of relationship and the application of different methodologies for phylogenetic reconstruction. These issues formed the nucleus of the 2nd Workshop which was convened to explore new and concrete ideas for future progress in tapeworm systematics and to standardize research programs at the international level with emphasis on phylogenetic analysis.

The structure and rationale for the Workshop were novel in providing a catalyst for development of a synoptic phylogeny for the Eucestoda. Seven working groups were established in October 1995 to represent: (1) Relationships at the level of order (chair: E. P. Hoberg, U. S. Department of Agriculture, MD, USA); (2) Molecular systematics J. Mariaux, Museum d'Histoire Naturelle, Geneva, Switzerland); (3) Ultrastructural characters J.-L. Justine, Laboratoire des Vers, Muséum National d'Histoire Naturelle, Paris, France); (4) Pseudophyllidea (R. A. Bray, British Museum of Natural History, London, UK); (5) Tetraphyllidea, Trypanorhyncha and associated orders (R. A. Campbell, University of Massachusetts, Dartmouth, USA); (6) Proteocephalidea (A. Rego, Institute Oswaldo Cruz, Rio de Janeiro, Brazil); and (7) Cyclophyllidea (A. Jones, International Institute of Parasitology, St. Albans, UK).

The initial days of the meeting involved intense discussions (12-14 h per day for some groups) to define current knowledge for comparative morphology among taxa from the ordinal to generic levels. These deliberations were highly focused, energetic and enthusiastically supported. Each Working Team produced a summary of characters representing putative homologies for morphological (ultrastructure and attributes visible at the level of light microscopy), ontogenetic, or molecular seqence data. The development of character matrices, generated from character descriptions and definition of transformation series, constituted the basis for preliminary phylogenetic hypotheses [analysis with PAUP 3.1.1 (Ref. 7), and MacClade 3.05 (Ref. 8)], which will now be refined through further analysis prior to publication in Systematic Parasitology and the Journal of Parasitology.

The 'hands-on' approach to phylogenetic reconstruction (attempted here on a workshop scale for the first time) was highly successful, and led to what has been described as a 'paradigm shift' within the community of systematists working on the Eucestoda. A solid foundation and new direction for research on the Eucestoda, based on phylogenetic approaches, has been firmly established. As a result of this Workshop, the critical comparisons resulting from character analysis and supportive contrasts provided by phylogenetic analysis and classical systematic classifications appear to have been widely appreciated by the participants.

\section{A Refined View of the Cestode World}

Among the most significant contributions were the novel phylogenetic hypotheses for orders of the Eucestoda presented by E. P. Hoberg, J. Mariaux (with P. Olson, University of Connecticut, USA) and J.-L. Justine, based, respectively, on morphological, molecular and ultrastructural characters. Incongruence among these hypotheses was primarily limited to relationships among the $\mathrm{Cy}$ clophyllidea, Proteocephalidea, Nippotaeniidea, Tetraphyllidea and Tetrabothriidea. For example, a strongly supported phylogenetic tree for the 12 orders based on comparative morphology (47 binary and multistate characters; consistency in$\operatorname{dex}=0.84)$ postulated a relationship for the Proteocephalidea \& Cyclophyllidea and the Tetraphyllidea \& Tetrabothriidea (analysis subsequent to the meeting now suggests that the Tetrabothriidae may be the sister group of the Cyclophyllidea). In contrast, a molecular tree derived from a partial sequence of $18 \mathrm{~S}$ rDNA supported a close relationship for the Proteocephalidea and Tetraphyllidea and placement of the Tetrabothriidea as a basal group within the Cyclophyllidea. Instability in these hypotheses is linked to the placement of the Tetrabothriidea, and it appears that this enigmatic group found only in marine birds and mammals ${ }^{9}$ may be one of the keys to understanding the relationships of the 'higher cestodes.' Another highlight of the meeting was the presentation by J.-L. Justine, who provided putative support for the molecular hypothesis based on ultrastructural and developmental characters of spermatozoa. Spirited discussions followed, focusing on resolution of relationships among the orders based on an integration of morphology and molecules.

Other notable contributions covered ordinal and family level groups. A robust hypothesis supporting the Proteocephalidean subfamilies, monophyly of the Monticellidae, and historical biogeographic relationships centering on Gondwanaland was given by 1 . Scholz (Institute of Parasitology, Czech Academy of Sciences), A. de Chambrier (Museum d'Histoire Naturelle, Geneva) and A. Rego. Relationships at the family level 
within the Cyclophyllidea were addressed by $\mathrm{A}$. Jones and also included recognition of monophyly for the Metadilepididae \& Paruterinidae by B. Georgiev (Laboratory of Parasite Biodiversity, Bulgarian Academy of Sciences), along with analyses of the subfamilies of the Hymenolepididae, genera of the Anoplocephalidae, and species of Taenia. Resolution of major systematic issues within the Tetraphyllidea and Trypanorhyncha were discussed by R. Campbell, L. Euzet and I. Beveridge (University of Melbourne, Australia) including the first phylogenetic trees for the Trypanorhyncha, Phyllobothriidae (T. Ruhnke, West Virginia State College) and Onchobothriidae (J. Caira, University of Connecticut, USA).

In the final day of the meeting, these phylogenetic hypotheses were presented for general discussion. The results of analyses and level of resolution, although preliminary, represented the first attempt to develop a comprehensive knowledge of relationships for the Eucestoda. Clearly, the new hypotheses resulted from the extraordinary cooperation and synergism generated during the Workshop.

\section{The Future}

Based on these initial phylogenetic hypotheses, the tapeworms now must be considered among the best-resolved taxa. The stage is set for rapid advances in our understanding of the evolutionary history of the Eucestoda. Progress is dependent on identification of gaps in our knowledge, recognition of new characters, and new concepts for interpretation. Ultimately the goal is to assess the total evidence, derived from a diversity of data sets, including morphological characters and multiple gene systems to achieve new phylogenetic insights.

We continue to be constrained by our limited knowledge of structural attributes. $^{1,2,6}$ Of crucial importance are studies of scolex morphology, and the development of concepts for homology of apical structures. Uterine ontogeny and structure have been adequately defined for relatively few taxa. Current data for spermiogenesis and ultrastructure of spermatozoons are sporadic, limited to a few species, and must be examined for their generality within and among taxa. We also still require life history information, particularly ontogenetic and morphological studies of metacestodes. Emphasis must remain on histology, electronmicroscopy and ultrastructural characters within the context of comprehensive comparative morphology for specific organ systems, as exemplified by the studies by F. Bona (University of Torino, Italy). Resolution of the incongruence between hypotheses based, respectively, on comparative morphology and molecular analysis, is a central issue.

Progress in systematics is vital to support a diversity of basic and applied programs dealing with cestodes and other helminth parasites. ${ }^{5,6}$ However, support for systematics has been minimal and, as a consequence, the numbers of biologists trained to work critically with tapeworms has been dramatically diminished in the past decade. The numbers of scientists attending (35), and the average age of those participating (around 50), highlights the current plight of systematics in parasitology. Conditions in Eastern Europe and the former Soviet Union continue to deteriorate and represent a significant threat to systematic biology. This is a tumultuous time as we approach the end of the century; however, we have the opportunity to provide a new and solid foundation and direction for advances in cestode systematics. Thus, this Workshop has contributed a fundamental continuity for scientific progress, basic research and education. These will constitute the cornerstone for the 3rd International Workshop to be convened by Boyko Georgiev in 1999 at the Institute of Ecology, Laboratory of Parasite Biodiversity, Sofia, Bulgaria.

\section{Acknowledgements}

The 2nd International Workshop for Tapeworm Systematics was held at the University of Nebraska, Lincoln, October 2-6, 1996, with the theme of promoting a broadbased phylogenetic research program on cestodes. Thirty-five scientists representing 18 countries participated, including nearly all current world authorities on cestode taxonomy and character analysis. We sincerely thank the participants who freely shared their knowledge and ideas, resulting in a truly synergistic Workshop. We acknowledge the efforts of Niki Gulseth, and Mauritz 'Skip' Sterner, of the Manter Laboratory, and Judith Holland of the Biosystematics and National Parasite Collection Unit, in ensuring a productive meeting. The Workshop was generously supported by grants and other resources from the American Society of Parasitologists, Agricultural Research Service (Office of the Director, Beltsville Area Research Center; and BNPCU), University of Nebraska-Lincoln (H. W. Manter Laboratory; and Office of the Chancellor), Foreign Agricultural Service, USDA, the United States Civilian Research and Development Foundation (CRDF) for the Independent States of the Former Soviet Union, Pfizer Inc., and private donations.

\section{References}

1. Mariaux, J. and Vaucher, C. (1994) Parasitology Today 10: 43-44.

2. Brooks, D. R., Hoberg, E. P. and Weekes, P. J. (199I) Proc. Biol. Soc. Wash. 104: 651-668.

3. Brooks, D. R. and McLennan, D. A. (1993) Parascript, Parasites and the Language of Evolution, Smithsonian Institution Press.

4. Khalil, L. F., Jones, A. and Bray, R. A. (1994) Keys to the Cestode Parasites of Vertebrates, CAB International.

5. Hoberg, E. P. (1996) in Biodiversity II: Understanding and Protecting Our Biological Resources (Reaka-Kudla, M. L., Wilson, D. E, and Wilson, E. O., eds.), pp. 243-261, Joseph Henry Press.6. Mariaux, J. (1996) Int. J. Parasitol. 26: 231-243.

7. Swofford, D. L. (1993) PAUP: Phylogenetic Analysis Using Parsimony, Version 3.1.1, Illinois Natural History Survey.

8. Maddison, W. P. and Maddison, D. R. (1995) MacClade: Analysis of Phylogeny and Character Evolution. Version 3.05, Sinauer Associates.

9. Hoberg, E. P. (1994) in Keys to the Cestode Parasites of Vertebrates (Khalil, L. F., Jones, A. and Bray, R. A., eds.), pp. 295304, CAB Intemational.

Eric Hoberg is at the Biosystematics and National Parasite Collection Unit Agricultural Research Service, U.S. Department of Agriculture BARC East No. 1180, 10300 Baltimore Avenue, Beltsville, MD 20705, USA. Scott Gardner is at the Harold W. Manter Laboratory, University of Nebraska State Museum, University of Nebraska, Lincoln, NE 68588, USA. Ronald Campbell is at the Department of Biology, University of Massachusetts, Dartmouth, 285 Old West Point Road, North Dartmouth, MA 02747, USA. Tel: +1 301504 8588, Fax: +1 301504 8979, e-mail: ehoberg@ggpl.arsusda.gov, slg@unl.edu. 